\title{
Influence of News in Moscow and New York on Returns and Risks on Baltic State Stock Indices*
}

\author{
Kurt Brännäs and Albina Soultanaeva \\ Department of Economics, Umeå University \\ SE-901 87 Umeå, Sweden \\ email: kurt.brannas@econ.umu.se and albina.soultanaeva@econ.umu.se
}

\begin{abstract}
The impact of news of the Moscow and New York stock market exchanges on the returns and volatilities of the Baltic state stock market indices is studied using daily return data for the period of 2000-2005. A nonlinear time series model that accounts for asymmetries in the conditional mean and variance functions is used for the empirical work. News from New York have stronger effect on returns in Tallinn, than news from Moscow. High risk shocks in New York have a strong impact on volatility in Tallinn, whereas volatility of Vilnius is more influenced by high risk shocks from Moscow. Riga seems to be autonomous to news arriving from abroad.
\end{abstract}

Key Words: Estonia, Latvia, Lithuania, Time series, Estimation, Finance.

JEL Classification: C22, C52, G10, G15.

Umeå Economic Studies 696, 2006

\footnotetext{
${ }^{*}$ The financial support from the Wallander-Hedelius Foundation is gratefully acknowledged. The comments from seminar audiences at SIFR and Umeå University and Jan G De Gooijer on a previous version of the paper were very useful.
} 


\section{Introduction}

In this paper we study price and volatility transmissions from the two leading US and Russian markets to Baltic states' stock markets. The Baltic stock exchanges started trading only quite recently. The Lithuanian stock exchange (VSE) re-opened in 1993. The trading on the Latvian stock exchange (RSE) started in mid 1995, while Estonia (TSE) opened up its stock exchange in the spring of 1996. All three markets have performed very well. For example, in 2004 the stock index of the RSE grew by 43.5 percent, and the TSE and VSE by 57.1 and 68.2 percent, respectively. Over the same period the NYSE composite (US) and the RTS (Russia) indices increased by 12.6 and 8.3 percent, respectively.

A substantial amount of research has been devoted to studying links between national stock markets. Most studies examine mean and volatility spillovers across international stock markets and some of the emerging markets, while less attention has been paid to the transition economies of Central and Eastern Europe. Hermes and Lensink (2000) review some issues related to the role of stock markets of transition economies. Rockinger and Urga (2000) test whether some of the transitional stock markets become more efficient over time and more integrated with other established markets. No Baltic stock markets are included in the study. Pajuste et al. (2000) study different aspects of the risk structure and its role in the return generating process in five Central and Eastern European markets, including Estonia. Kairys et al. (2000) study the impact of changes in the microstructure of the Riga Stock exchange (RSE) on the liquidity in this market.

It is fairly well established that not only domestic new information but also information from other markets can be incorporated in the pricing of domestic securities. In this paper we are interested in the extent to which Baltic stock market index returns are influenced by news arriving from Russia (Moscow, RTS) and US (New York, NYSE Composite). News affecting the price process are divided into good and bad news. The term "good news" is used to denote positive past returns, whereas the term "bad news" denotes negative past returns.

We are also interested in whether changes in volatility in Baltic stock markets are related to changes in return volatilities observed in the Russian and US markets. Volatility shocks from abroad are divided into "high" and "low" volatility. Ross (1989) argues that market volatility is related to the flow of information to the market. Then, assuming that the information from the Russian and US stock markets is relevant for three Baltic stock markets, the return volatility might be affected by volatility shocks from abroad.

The current study builds on previous research in several ways. First, we study price and volatility transmission from the two US and Russian marketplaces to three Baltic markets. Earlier studies have found empirical evidence of significant return and volatility spillovers from the US market to other national stock markets (e.g., Liu and Pan, 1997; Eun and Shim, 1989; Koch and Koch, 1991). This is consistent with the US market being 
the most influential producer of information. Tse et al. (2003) found that the volatility of the Warsaw Stock Exchange is not influenced by past US market volatility, but they also found that there is a significant spillover in the return from the US market on the Polish stock market. Spillovers from the Russian stock market may be explained by the economic and historical ties between the countries. In addition, Pajuste et al. (2000) argue that geographic proximity can measure the level of a country's integration, i.e. countries that are closer to Russia are more influenced by its risk. Obviously, an interesting issue is whether the Baltic States stock markets are more influenced by news from the major US stock markets rather than by the Russian market.

We employ an econometric model that is designed to catch asymmetric impacts of good and bad news on the price and volatility. For instance, Black (1976) noted the asymmetric impact of good and bad news on volatility, where bad news increase volatility more than good news. This asymmetry is sometimes described as a leverage effect. However, for emerging markets it is possible that positive innovations increase volatility more than negative innovations. Rockinger and Urga (2000) found this pattern for Hungary, and suggest that "for countries, suffering from low liquidity, one can imagine scenarios where good news can lead to increased liquidity, which in turn can lead to increased volatility as investors rebalance their portfolios". This feature is called the liquidity hypothesis. Similar results were found by Bekaert and Harvey (1997) for some emerging countries. Previous studies (e.g., Koutmos and Booth, 1995) have found that the volatility transmission is also often asymmetric with respect to positive and negative innovations. It is also possible that the conditional mean responds asymmetrically to past innovations (Koutmos, 1998; Wecker, 1981). To capture such features we combine the ARasMA model of Brännäs and De Gooijer (1994) for the conditional mean with an asymmetric parameterization of the conditional variance. The volatility process is modelled as an asymmetric extension of the quadratic GARCH model of Sentana (1995). The resulting ARasMA-asQGARCH model (Brännäs and De Gooijer, 2004) allows us to detect asymmetry in both conditional mean and variance of stock return data. We extend this model to also capture any potential asymmetric impact of good and bad news from the two US and Russian marketplaces.

The remainder of the paper is organized as follows. Section 2 introduces the ARasMAasQGARCH model and presents the estimation method. Section 3 discusses the data and Section 4 gives the empirical results. The major findings are summarized in the final section.

\section{Model and Estimation}

To account for the possibly asymmetric effects of news in Moscow (RTS) and New York (NYSE) on the stock market indices of the Baltic states we expand the conditionally heteroskedastic ARasMA specification of Brännäs and De Gooijer (2004), hereafter BDG (see also Wecker, 1991; Brännäs and De Gooijer, 1994). The news effects are allowed 
to impact both the conditional mean (return) and heteroskedasticity (volatility or risk) functions.

Let $\left\{u_{t}\right\}$ be a real-valued discrete-time stochastic process generated by

$$
u_{t}=\varepsilon_{t} h_{t}
$$

where $\left\{\varepsilon_{t}\right\}$ is a sequence of independent and identically distributed random variables with mean zero and unit variance, and the conditional standard deviation $h_{t}$ is independent of $\varepsilon_{t}$ as well as non-negative for all $t$. Further, let

$$
u_{t}^{+}=\max \left(0, u_{t}\right)=\varepsilon_{t}^{+} h_{t} \quad \text { and } \quad u_{t}^{-}=\min \left(u_{t}, 0\right)=\varepsilon_{t}^{-} h_{t}
$$

where $\varepsilon_{t}^{+}=\max \left(0, \varepsilon_{t}\right)$ and $\varepsilon_{t}^{-}=\min \left(\varepsilon_{t}, 0\right)$. In an analogous way, let $x_{t}^{+}=\max \left(0, x_{t}\right)$ and $x_{t}^{-}=\min \left(0, x_{t}\right)$ be the positive and negative return at time $t$, respectively, in the Moscow and/or New York return series.

The autoregressive asymmetric moving average (ARasMA) model of order $(p, r, q)$, is then defined as

$$
\begin{aligned}
y_{t}= & \sum_{i=1}^{p} \alpha_{i} y_{t-i}+\sum_{i=1}^{r}\left(\gamma_{i}^{+} x_{t-i}^{+}+\gamma_{i}^{-} x_{t-i}^{-}\right)+\beta_{0}+u_{t}+\sum_{i=1}^{q}\left(\beta_{i}^{+} u_{t-i}^{+}+\beta_{i}^{-} u_{t-i}^{-}\right) \\
= & \sum_{i=1}^{p} \alpha_{i} y_{t-i}+\sum_{i=1}^{r}\left(\gamma_{i}^{-} x_{t-i}+\gamma_{i}^{\nabla} I\left(x_{t-i} \geq 0\right) x_{t-i}\right)+\beta_{0} \\
& +u_{t}+\sum_{i=1}^{q}\left(\beta_{i}^{-} u_{t-i}+\beta_{i}^{\nabla} I\left(u_{t-i} \geq 0\right) u_{t-i}\right) .
\end{aligned}
$$

Here, $\gamma_{i}^{\nabla}=\gamma_{i}^{+}-\gamma_{i}^{-}, i=1, \ldots, r, \beta_{i}^{\nabla}=\beta_{i}^{+}-\beta_{i}^{-}, i=1, \ldots, q$, and $I(\cdot)$ is the indicator function. Since the values of the $\beta_{i}^{+}$and $\beta_{i}^{-}$parameters at the $i$ th lag may be different, the response to equally sized positive and negative shocks may be different or asymmetric. The inherent asymmetry of the asMA model was illustrated numerically by Brännäs and Ohlsson (1999). Obviously, if $\gamma_{i}^{+}=\gamma_{i}^{-}$for all $i$, the response to positive and negative news in the Moscow and/or New York return series is symmetric.

The conditional mean (return) of $y_{t}$ given past observations is

$$
E\left(y_{t} \mid Y_{t-1}\right)=\sum_{i=1}^{p} \alpha_{i} y_{t-i}+\sum_{i=1}^{r}\left(\gamma_{i}^{+} x_{t-i}^{+}+\gamma_{i}^{-} x_{t-i}^{-}\right)+\beta_{0}+\sum_{i=1}^{q}\left(\beta_{i}^{+} u_{t-i}^{+}+\beta_{i}^{-} u_{t-i}^{-}\right) .
$$

Note that containing several rather than one $x_{t}$ series in the model presents no additional difficulty.

Various models have been proposed to represent the conditional heteroskedasticity $h_{t}^{2}$ in (1). Sentana (1995) introduced the QGARCH $(P, P)$ model and BDG the Asymmetric Quadratic Generalized ARCH (asQGARCH) model of order $(Q ; P, P)$. To account for asymmetric effects through a variable $z_{t}$ from Moscow and/or New York we expand the 
latter to obtain

$$
\begin{aligned}
h_{t}^{2}= & \alpha_{0}+\sum_{i=1}^{R}\left(\eta_{i}^{+} z_{t-i}^{+}+\eta_{i}^{-} z_{t-i}^{-}\right)+\sum_{i=1}^{Q}\left(\alpha_{i}^{+} u_{t-i}^{+}+\alpha_{i}^{-} u_{t-i}^{-}\right)+\sum_{i=1}^{P} \kappa_{i} u_{t-i}^{2}+\sum_{i=1}^{P} \rho_{i} h_{t-i}^{2} \\
= & \alpha_{0}+\sum_{i=1}^{R}\left(\eta_{i}^{-} z_{t-i}+\eta_{i}^{\nabla} I\left(z_{t-i} \geq 0\right) z_{t-i}\right)+\sum_{i=1}^{Q}\left(\alpha_{i}^{-} u_{t-i}+\alpha_{i}^{\nabla} I\left(u_{t-i} \geq 0\right) u_{t-i}\right) \\
& +\sum_{i=1}^{P} \kappa_{i} u_{t-i}^{2}+\sum_{i=1}^{P} \rho_{i} h_{t-i}^{2} .
\end{aligned}
$$

The first term of this conditional variance (risk) function accounts for asymmetric effects in either or in both of the Moscow and New York series around some threshold level $\bar{z}$, the second block on the right-hand side describes the asymmetry in the conditional variance. The former part of $u_{t}^{+}$and $u_{t}^{-}$may cause a problem with the positivity of $h_{t}^{2}$ unless parameters are constrained, e.g., such that the effects of $u_{t-i}$ and $u_{t-i}^{2}$ are positive. In (3) positive shocks have a different effect than negative shocks. The response of the process is parabolic, though not symmetric around zero.

If $\alpha_{i}^{\nabla}=0$ for all $i=1, \ldots, Q$ and $Q=P,(3)$ reduces to an extended $\operatorname{QGARCH}(P, P)$. We also see that when $\alpha_{i}^{+}=\alpha_{i}^{-}=0,(3)$ simplifies to the extended GARCH model of order $(P, P)$ introduced by Bollerslev (1986). Note, however, that in the case of $Q=P=1$, (3) differs from the so-called Asymmetric Threshold GARCH (asTGARCH) of order $(1 ; 1,1)$ of Koutmos (1999) which is an asymmetric analogue of the TGARCH(1,1) model of Zakoïan (1994).

Unconditional moments are hard to obtain, but are given for the case of no $x_{t}$ and $z_{t}$ variables in BDG and for a model with constant $h_{t}^{2}$ by Brännäs and De Gooijer (1994) for normally distributed $\left\{\varepsilon_{t}\right\}$ sequences. Some related model properties for log-generalized gamma and Pearson IV distributed $\left\{\varepsilon_{t}\right\}$ sequences are discussed by Brännäs and Nordman (2003ab).

\subsection{Empirical Modelling Strategy}

To find empirical models we adopt a procedure in four steps. First, we find the best ARasMA model for each Baltic stock exchange. Next, in the second step this ARasMA model is augmented with an asQGARCH model for conditional heteroskedasticity. In a third step, we expand each specification of the second step by, in turn, including Moscow and New York both in the conditional mean and conditional variance functions. This allows us to test whether Moscow and/or New York cause mean returns or volatilities. The conditional mean and variance functions are allowed to respond asymmetrically to news in the Moscow and New York series. Finally, both Moscow and New York are incorporated in the same model. In each step we employ the AIC criterion to find a parsimonious parametrization. 


\subsection{Estimation}

Conditional on $Y_{t-1}=\left(y_{1}, \ldots, y_{t-1}\right)$ the prediction error

$$
e_{t}=y_{t}-E\left(y_{t} \mid Y_{t-1}\right)
$$

has the distribution of $\varepsilon_{t} h_{t}$. BDG assumed $\left\{\varepsilon_{t}\right\}$ to be normally distributed so that the conditional density of $y_{t}$ given $Y_{t-1}$ is normal with mean $E\left(y_{t} \mid Y_{t-1}\right)$ and variance $h_{t}^{2}$. The log-likelihood function to be maximized with respect to the unknown parameters is then

$$
\ell=\sum_{t=r}^{T} \ln L_{t} \propto-\frac{1}{2} \sum_{t=r}^{T}\left(\ln h_{t}^{2}+\frac{e_{t}^{2}}{h_{t}^{2}}\right) .
$$

The log-likelihood function is not continuous in the indicator function. Qian (1998) derived asymptotics for the maximum likelihood estimator for a two regime self-exciting threshold model where errors are not necessarily normally distributed. This particular model is dual to an asMA model which is a special case of (2). Hence, the usual asymptotic inference on the estimated parameters still holds and then also applies to an asMA model. The same indicator functions re-appear when the model contains conditional heteroskedasticity in the form of (3). We propose that consistency and asymptotic normality remain to hold.

As an estimator of the covariance matrix we use the robust sandwich form

$$
\operatorname{Cov}(\hat{\boldsymbol{\theta}})=\left(\sum_{t=r}^{T} \frac{\partial^{2} \ln L}{\partial \hat{\boldsymbol{\theta}} \partial \hat{\boldsymbol{\theta}}^{\prime}}\right)^{-1} \sum_{t=r}^{T} \frac{\partial \ln L_{t}}{\partial \hat{\boldsymbol{\theta}}} \frac{\partial \ln L_{t}}{\partial \hat{\boldsymbol{\theta}}^{\prime}}\left(\sum_{t=r}^{T} \frac{\partial^{2} \ln L}{\partial \hat{\boldsymbol{\theta}} \partial \hat{\boldsymbol{\theta}}^{\prime}}\right)^{-1}
$$

where $\boldsymbol{\theta}$ is the parameter vector and the expression is evaluated at the estimate $\hat{\boldsymbol{\theta}}$.

Hypotheses of symmetric responses in the conditional mean (cf. Brännäs and De Gooijer, 1994), the conditional variance, or in both jointly may be formulated as linear restrictions on the $\boldsymbol{\theta}$ vector, i.e. as $\mathbf{R} \boldsymbol{\theta}=\mathbf{0}$. Likelihood ratio tests are easy to apply in practice. Given the estimates and the covariance matrix estimator Wald testing is also quite straightforward.

For practical estimation the RATS 6.0 package is employed, using robust covariance matrices throughout.

\section{Data}

The data used in this paper are capitalization weighted daily stock price indices of the Estonian (Tallinn, TALSE), Latvian (Riga, RIGSE), Lithuanian (Vilnius, VILSE), Russian (Moscow, RTS) and the United States (NYSE Composite) stock markets. All indices are collected from web sites; WWW.OMXGROUP.COM provides the complete description of the Baltic stock market indices, while WWW.RTS.RU and WWW.NYSE.COM give the remaining indices. All prices are in local currencies, except for Estonia where stock market trading is in Euro. The dataset covers January 3, 2000 to April 29, 2005, for a total of $T=1391$ observations, cf. Figure 1 for all indices. It is quite obvious that growth 

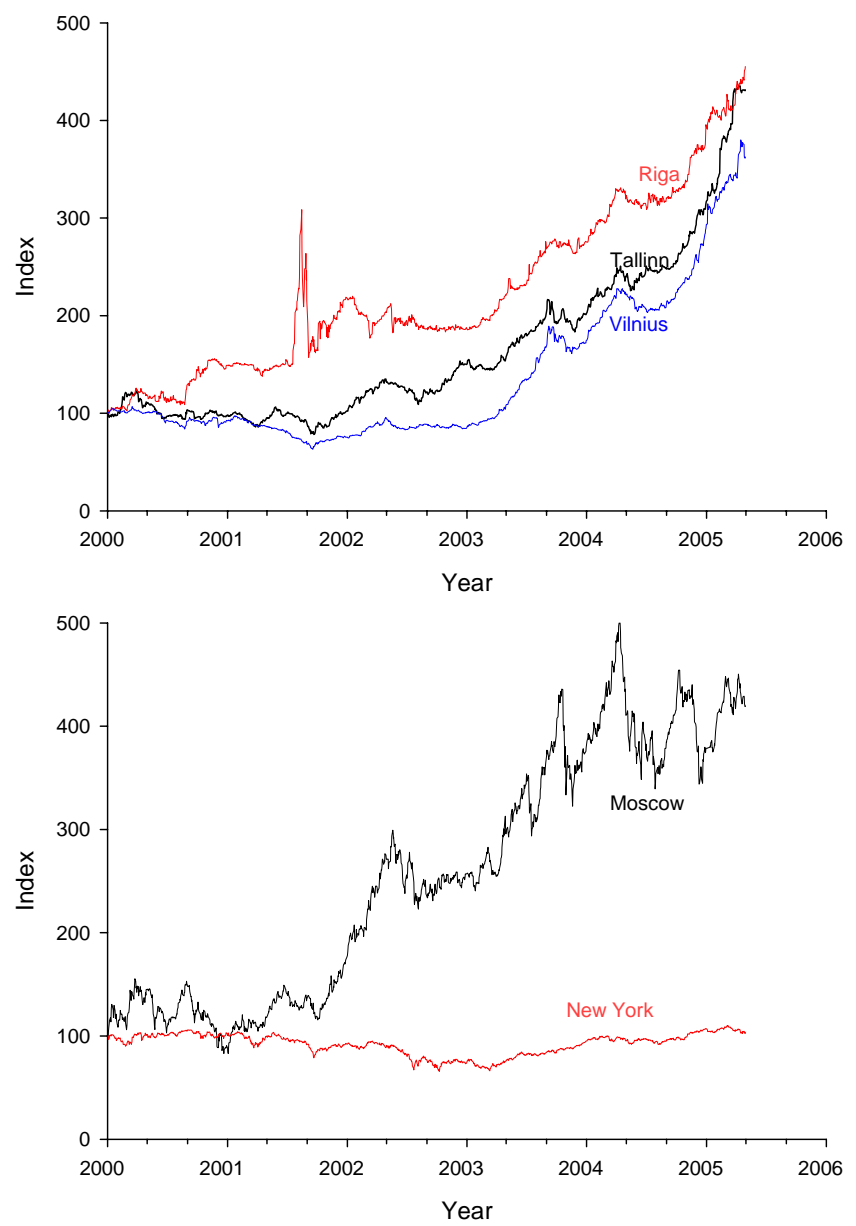

Figure 1: Indices of the Baltic stock exchanges, Moscow and New York (January 3, 2000 $=100)$.

rates are high but for New York and that the variance of Moscow is much higher than for other series. The irregularity after the 400th observation in the Riga index (RIGSE) is due to a power struggle in its largest company (Latvijas Gaze) in the summer of 2001. Instead of elaborating on modelling to contain this irregular period, the Riga series starts at September 17, 2001, and contains $T=945$ daily observations.

Due to differences in holidays for the involved countries the series have different shares of days for which index stock price are not observable. For Baltic stock market indices the number of missed trading days on comparison with New York, which is used as a standard, is 39 for TALSE, 49 for RIGSE, and 46 for VILSE for the entire sample. Linear interpolation was used to fill the gaps for all series. The resulting series are then throughout for a common trading week.

All returns are calculated as $y_{t}=100 \cdot \ln \left(I_{t} / I_{t-1}\right)$, where $I_{t}$ is the daily price index. 
Table 1: Descriptive statistics for daily return series.

\begin{tabular}{lcrrrrrr}
\hline \hline Exchange & Mean & Variance & Min/Max & Skewness & Kurtosis & LB 10 & T \\
\hline Riga & 0.10 & 1.57 & $-9.72 / 9.46$ & -0.04 & 15.46 & 57.74 & 945 \\
Tallinn & 0.11 & 1.13 & $-5.87 / 7.34$ & 0.20 & 5.68 & 47.80 & 1391 \\
Vilnius & 0.09 & 0.76 & $-10.22 / 4.58$ & -0.94 & 16.61 & 60.80 & 1391 \\
Moscow & 0.10 & 4.70 & $-11.57 / 9.62$ & -0.42 & 2.78 & 21.28 & 1391 \\
New York & 0.00 & 1.08 & $-5.27 / 5.18$ & 0.08 & 2.29 & 14.23 & 1391 \\
\hline
\end{tabular}

Note: $\mathrm{LB}_{10}$ is the Ljung-Box statistic evaluated at 10 lags.

Table 2: Cross-correlations for Baltic return series vs Moscow and New York.

\begin{tabular}{lrrrrrrrrrr}
\hline & \multicolumn{10}{c}{ Lag/Lead } \\
\cline { 2 - 10 } Exchange & -4 & -3 & -2 & -1 & 0 & 1 & 2 & 3 & 4 \\
\hline \multirow{8}{*}{ Riga } & 0.007 & .0007 & 0.020 & 0.005 & -0.041 & 0.041 & 0.012 & -0.002 & 0.003 \\
Tallinn & 0.061 & 0.062 & 0.055 & 0.051 & 0.165 & -0.048 & -0.038 & -0.043 & 0.008 \\
Vilnius & 0.081 & 0.078 & 0.059 & 0.079 & 0.076 & -0.028 & -0.043 & 0.032 & 0.013 \\
& & & & & vs & New & York & & & \\
Riga & 0.010 & -0.005 & 0.077 & -0.010 & -0.001 & 0.005 & -0.006 & -0.031 & 0.036 \\
Tallinn & 0.027 & 0.039 & 0.033 & 0.260 & 0.076 & -0.040 & -0.026 & -0.004 & 0.025 \\
Vilnius & 0.081 & 0.078 & 0.059 & 0.079 & 0.076 & -0.028 & -0.043 & 0.032 & 0.013 \\
\hline
\end{tabular}

Table 1 reports descriptive statistics for the daily returns. With the exception of New York, the Ljung-Box statistic for 10 lags $\left(\mathrm{LB}_{10}\right)$ indicates significant serial correlation. The large kurtoses for Riga and Vilnius indicate leptokurtic densities. The returns of Moscow and/or New York serve as the $x_{t}$ variables in (2). For the $z_{t}$ of the conditional variance function in (3) we construct two new series for Moscow and New York, by obtaining moving variances for a window length of 10 observations. For Moscow the sample mean is 4.65 with a variance of 28.83, while for New York the sample moments are much lower; 1.09 and 1.57. The $z_{t}$ series entering the conditional variance function are demeaned moving variance series; the threshold is then set at zero. The $z^{+}$then takes on positive values and is indicative of high risk, and $z^{-}$in a corresponding way takes on negative values and indicates lower risk in Moscow and/or New York.

Table 2 gives cross-correlation functions for the return series vs Moscow and New York. There are several interesting features to note. First, Riga appears autonomous with no significant influence of neither Moscow nor New York. Second, Vilnius is throughout positively influenced by both Moscow and New York. Third, for Tallinn there is a strong positive impact of lagged Moscow returns within the same day, while with respect to 
New York yesterdays returns have the strongest impact followed by the current day. This mirrors the synchronization difficulty we face due to differences in time zones. Therefore, in model estimations New York is throughout incorporated with, at least, one lag to account for the time difference between the Baltic states and the US. Finally and not surprisingly given their sizes, the Baltic stock exchanges appear to exert no significant impact on neither the Moscow nor the New York stock returns.

\section{Results}

The final estimation results are presented in Table 3, and were obtained by the stepwise procedure outlined in Section 2.1. Tables A1-A6 of the Appendix give estimation results for the preceding steps of the specification procedure. We start by discussing the results for Tallinn in some detail and later progress to briefer accounts for the Riga and Vilnius exchanges.

The estimation results for AIC minimizing pure ARasMA models are reported in Table A1 of the Appendix. Focusing on Tallinn, all parameters of the pure ARasMA model are significantly different from zero. In this model a Wald test rejects the hypothesis of symmetric response to shocks at the included lags $(p<0.001)$ and the $\mathrm{LB}_{10}$ statistic indicates that the standardized residuals, $\hat{u} / \hat{h}$, are uncorrelated up to 10 lags, whereas the squared standardized residuals show significant serial correlation $\left(\mathrm{LB}_{10}^{2}=12.98, p=0.22\right)$.

The pure ARasMA model is rejected in favour of the ARasMA-asQGARCH specification of Table A2 $(\mathrm{LR}=145.4)$. In the extended model neither standardized nor squared standardized residuals show any significant serial correlation. A characteristic feature of the fitted ARasMA-asQGARCH model in Table A2, columns 3-4, is that a negative shock at lag one has a rather large risk-enhancing effect on conditional heteroskedasticity. The squared shock at lag two has a small negative parameter estimate. The asymmetric effect due to a shock in the conditional heteroskedasticity specification is longlasting since estimates of $h_{t-1}$ are about 0.9 . In the conditional mean function the AR parameter prolongs the effects of shocks somewhat.

In the next step, we separately add lags of Moscow and New York returns series to the conditional mean (ARasMA) function. Tables A3-A4 give the estimation results for such extended model specifications. We allow for asymmetric response to good and bad news in the Moscow or New York series. For the conditional mean of Tallinn, Moscow explains around 4 percent of returns, while news from New York seem to explain about 8 percent.

Tables A5-A6 report estimation results for models with either Moscow or New York lags in both the conditional mean and variance functions. The LR test statistics reject restricted models (cf. Tables A3-A4) against extended models for Tallinn. A characteristic feature of these model, is that positive shocks (i.e. high risk) from New York and Moscow seem to have a larger effect on volatility in Tallinn, than the insignificant negative ones (lower risks). 
Table 3: Parameter estimates for the joint conditional return and risk functions of ARasMA-asQGARCH models with both Moscow and New York in the functions (robust standard errors in parentheses).

\begin{tabular}{|c|c|c|c|c|c|c|}
\hline \multirow[b]{2}{*}{ Variable } & \multicolumn{2}{|c|}{ Riga } & \multicolumn{2}{|c|}{ Tallinn } & \multicolumn{2}{|c|}{ Vilnius } \\
\hline & Return & Risk & Return & Risk & Return & Risk \\
\hline$y_{t-1}$ & & & $0.123(0.080)$ & & & \\
\hline$y_{t-2}$ & & & & & $0.106(0.026)$ & \\
\hline$u_{t-1}^{+}$ & $-0.157(0.062)$ & & $0.139(0.089)$ & $0.169(0.106)$ & $0.310(0.052)$ & $-0.239(0.118)$ \\
\hline$u_{t-2}^{+}$ & & & & $0.087(0.113)$ & & $0.431(0.100)$ \\
\hline$u_{t-3}^{+}$ & & & $-0.075(0.030)$ & & & \\
\hline$u_{t-1}^{-}$ & $-0.026(0.074)$ & $0.153(0.116)$ & $-0.058(0.090)$ & $-0.468(0.107)$ & & $0.261(0.127)$ \\
\hline$u_{t-2}^{-}$ & & $-0.042(0.098)$ & & $0.236(0.111)$ & & $-0.385(0.103)$ \\
\hline$u_{t-3}^{-}$ & & & & & $0.040(0.048)$ & \\
\hline$u_{t-4}^{-}$ & & & $0.090(0.038)$ & & & \\
\hline$u_{t-1}^{2}$ & & $0.512(0.065)$ & & $0.046(0.051)$ & & $0.295(0.079)$ \\
\hline$u_{t-2}^{2}$ & & $-0.202(0.068)$ & & $-0.087(0.048)$ & & $-0.203(0.067)$ \\
\hline$h_{t-1}$ & & $0.630(0.048)$ & & $0.914(0.014)$ & & $0.673(0.049)$ \\
\hline$x, z_{M, t}^{+}$ & $-0.027(0.031)$ & & $0.014(0.019)$ & & $-0.009(0.018)$ & \\
\hline$x, z_{M, t-1}^{+}$ & $-0.027(0.031)$ & & $0.000(0.019)$ & $-0.014(0.007)$ & $0.025(0.018)$ & $-0.017(0.013)$ \\
\hline$x, z_{M, t-2}^{+}$ & & & $-0.017(0.018)$ & $0.013(0.007)$ & $-0.006(0.018)$ & $0.091(0.023)$ \\
\hline$x, z_{M, t-3}^{+}$ & & & $0.040(0.021)$ & & & $-0.117(0.021)$ \\
\hline$x, z_{M, t-4}^{+}$ & & & & & & $0.048(0.014)$ \\
\hline$x, z_{M, t}^{-}$ & $0.053(0.030)$ & & $0.076(0.017)$ & & $0.048(0.016)$ & \\
\hline$x, z_{M, t-1}^{-}$ & $-0.010(0.034)$ & $0.036(0.009)$ & $-0.028(0.021)$ & & $0.017(0.017)$ & $0.002(0.023)$ \\
\hline$x, z_{M, t-2}^{-}$ & & & $0.059(0.019)$ & & $0.023(0.019)$ & $0.007(0.024)$ \\
\hline$x, z_{M, t-3}^{-}$ & & & $0.023(0.017)$ & & & \\
\hline$x, z_{N Y, t-1}^{+}$ & $-0.025(0.050)$ & $0.015(0.011)$ & $0.202(0.043)$ & $0.186(0.044)$ & $0.056(0.032)$ & \\
\hline$x, z_{N Y, t-2}^{+}$ & & & & & & $-0.023(0.031)$ \\
\hline$x, z_{N Y, t-3}^{+}$ & & & & $-0.453(0.121)$ & & $-0.005(0.072)$ \\
\hline$x, z_{N Y, t-4}^{+}$ & & & & $0.269(0.083)$ & & $0.021(0.043)$ \\
\hline$x, z_{N Y, t-1}^{-}$ & $0.015(0.048)$ & $-0.060(0.022)$ & $0.220(0.037)$ & & $0.071(0.037)$ & $0.017(0.093)$ \\
\hline$x, z_{N Y, t-3}^{-}$ & & & & & & $0.049(0.233)$ \\
\hline$x, z_{N Y, t-4}^{-}$ & & & & & & $-0.110(0.167)$ \\
\hline Constant & $0.235(0.059)$ & $0.218(0.046)$ & $0.149(0.053)$ & $-0.040(0.007)$ & $0.071(0.050)$ & $0.069(0.030)$ \\
\hline$\hat{\sigma}^{2}, \mathrm{AIC}$ & 0.975 & 0.89 & 0.994 & 0.91 & 0.712 & 0.52 \\
\hline $\ln L$ & -402.15 & & -598.95 & & -328.23 & \\
\hline $\mathrm{LB}_{10}, \mathrm{LB}_{10}^{2}$ & 11.17 & 11.17 & 6.87 & 0.83 & 7.82 & 1.91 \\
\hline Skew, Kurt & 0.62 & 4.43 & 0.71 & 6.88 & -0.35 & 6.17 \\
\hline
\end{tabular}

Note: $\mathrm{LB}_{10}$ and $\mathrm{LB}_{10}^{2}$ is the Ljung-Box statistic for standardized residuals and their squares at lag 10. 
Table 3 reports estimation results for models with Moscow and New York incorporated jointly. Rather than including all lags of Moscow and New York numerical reasons forced us to adopt a leaner approach; the asQGARCH only contains those lags that were significantly different from zero in Tables A5-A6. The results suggest that only positive shocks from New York and Moscow have impact on volatility in Tallinn. Positive shocks from New York influence the volatility of Tallinn series more than shocks from Moscow. For the conditional returns of Tallinn, good news from New York have positive impact on returns in Tallinn. Bad news from Moscow at the same day and two days ago, as well as bad news from New York at one lag have negative impact on returns in Tallinn, through positive parameter values. Bad news from New York seem to have stronger impact on returns in Tallinn. There is no impact of good news on returns.

For Riga we find that there is no impact of neither good nor bad news from New York nor from Moscow on returns in Riga. For the conditional risk function, negative shocks (i.e. low risk) from Moscow reduce the volatility in Riga. High risk shocks from Moscow are not included in this final model specification. However, the results remain unaltered if insignificant lags of Moscow (as in Table A4) are included. Positive shocks from New York no longer have any impact on volatility in Riga, when both Moscow and New York are incorporated jointly in the conditional variance function. Negative shocks from New York have risk-enhancing effect through negative parameter value.

The final columns of Table 3 report the estimates of the full model for Vilnius. News arriving from New York and Moscow explain a modest 1.6 and 0.7 percent of returns dynamics for Vilnius, respectively. Good news from Moscow seem to have no effect on returns in Vilnius. The market reaction to bad news from Moscow is quite fast. Bad news from Moscow (i.e. negative returns) within the same day have negative impact on returns in Vilnius. For volatility spillovers, positive shock (i.e. high risk) from Moscow are the only ones to affect volatility in Vilnius. The volatility persistence is quite low for the final model specifications for Riga and Vilnius in Table 3.

In Figures 2-3 the conditional mean and variance responses to unit positive and negative shocks in Moscow and New York are plotted. It is obvious that shocks arising in New York have larger effects than those of Moscow on the returns of Tallinn and Vilnius. The duration of effects is longer for Moscow. Positive shocks (i.e. higher risk) from New York seem to have quite large risk enhancing effect in Tallinn, whereas positive shocks from Moscow have the strongest effect in Vilnius. Shocks from abroad seem to have quite little effect on returns and risks in Riga. Note, however, that variances of both return and risk are much larger for Moscow. Even though, say, one standard error sized shocks are employed, the results of Figures 2-3 remain qualitatively unchanged.

We use the Wald test statistic to test the hypothesis of no asymmetry in the final specifications of ARasMA-asQGARCH models. Test results are presented in Table 4. The null hypothesis of symmetric responses to own past shocks in conditional mean and variance can be rejected for the stock markets of Tallinn and Vilnius, in all three models. 

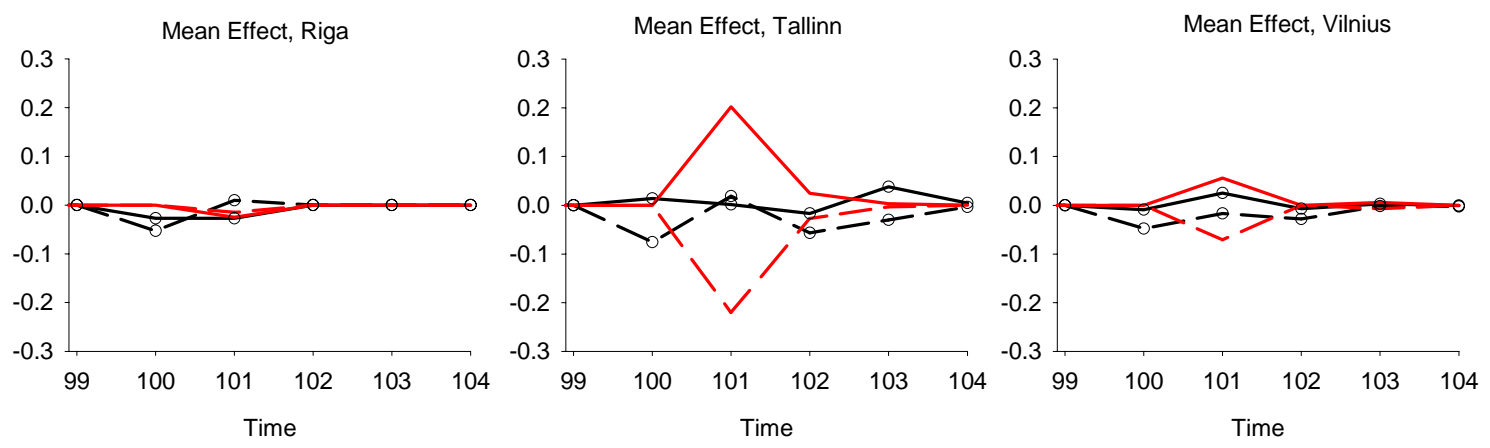

Figure 2: The effect of positive and negative shocks (at date $=100$ ) in Moscow and New York in the conditional return functions of the Riga, Tallinn and Vilnius modela. Effects are shifted to zero before the change date and $u_{t}=0$ for all $t$ (solid line with marker for positive shocks in Moscow, without marker in New York, and analogously for negative shocks and dashed lines).
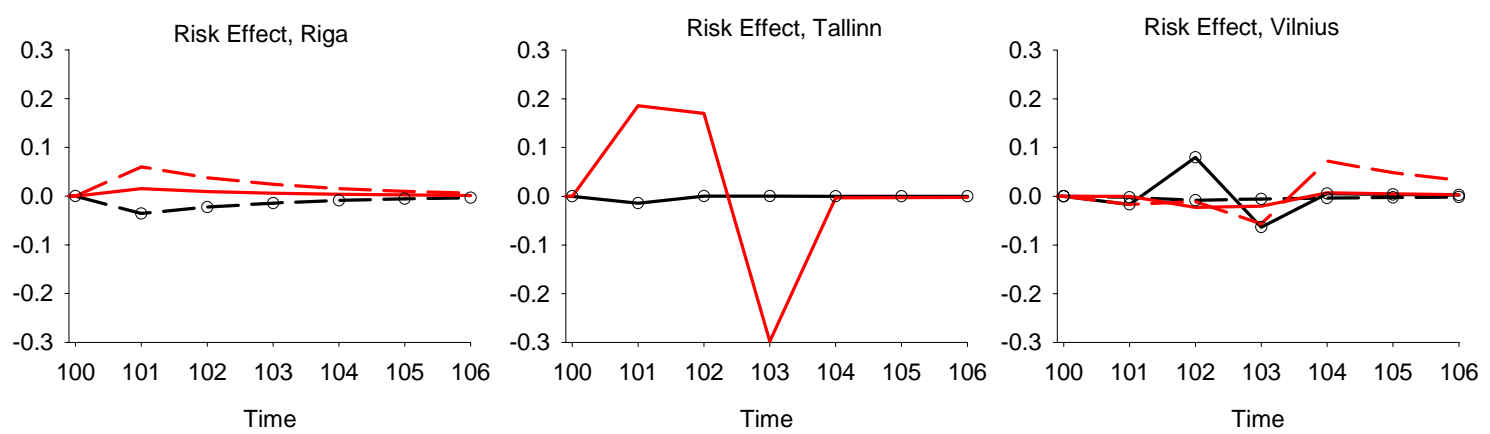

Figure 3: The effect of high and low risk shocks (at date $=100$ ) in Moscow and New York in the conditional volatility functions of the Riga, Tallinn and Vilnius models. Effects are shifted to zero before the change date and $u_{t}=0$ for all $t$ (solid line with marker for positive shocks in Moscow, without marker in New York, and analogously for negative shocks and dashed lines). 
Table 4: Summary of asymmetry tests (M for Moscow and NY for New York).

\begin{tabular}{|c|c|c|c|c|c|c|c|c|c|c|c|c|c|c|}
\hline \multirow{3}{*}{$\begin{array}{l}\text { Stock } \\
\text { Market }\end{array}$} & \multicolumn{4}{|c|}{ Table A5 } & \multicolumn{4}{|c|}{ Table A6 } & \multicolumn{6}{|c|}{ Table 3} \\
\hline & \multicolumn{2}{|c|}{ Return } & \multicolumn{2}{|c|}{ Risk } & \multicolumn{2}{|c|}{ Return } & \multicolumn{2}{|c|}{ Risk } & \multicolumn{3}{|c|}{ Returns } & \multicolumn{3}{|c|}{ Risk } \\
\hline & $u$ & M & $u$ & M & $u$ & NY & $u$ & NY & $u$ & NY & M & $u$ & NY I & M \\
\hline Rig & - & - & $*$ & $*$ & - & - & - & & - & - & - & - & $*$ & $*$ \\
\hline Tallin & $*$ & - & $*$ & - & $*$ & - & $*$ & * & . & - & $*$ & * & $*$ & $*$ \\
\hline Vilnius & * & - & $*$ & $*$ & $*$ & $*$ & $*$ & t & 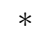 & - & - & $*$ & - & * \\
\hline
\end{tabular}

Note: $*$ indicates significance at the 5 percent level.

For the models that incorporate New York separately (Table A6), the null hypothesis of symmetric responses to shocks from New York in conditional variance can also be rejected. Wald tests rejected the hypothesis of symmetric impact of good and bad news from Moscow on returns for Tallinn, for the model presented in Table A5.

The final columns in Table 3 present the results for models that incorporates Moscow and New York jointly. The Wald test statistics suggests that there are asymmetries in responses to own past shocks in conditional mean and variance functions, except for the Riga series. The conditional first moments of Vilnius and Tallinn stock indices respond asymmetrically to news from Moscow, whereas there is no evidence for asymmetric response to good and bad news from New York for any of the three Baltic stock markets. For the conditional second moments, the Wald test indicates no asymmetric impact of news from New York on volatility in Vilnius and Tallinn. According to our test results for the final model, news from Moscow have asymmetric impact on volatility in all three countries under study.

\section{Discussion}

This study uses an extended ARasMA-asQGARCH model to examine information transmission from Moscow (RTS) and New York (NYSE) to three Baltic states stock markets, comprising Lithuania (Vilnius), Latvia (Riga) and Estonia (Tallinn). The hypothesis of asymmetric adjustment to own past information and information from abroad is tested. Our empirical results from examining the data for the period of 2000 to 2005 indicate the following.

First, for Tallinn there is a clear asymmetry in response to own past shocks for the conditional variance, where bad news generate larger volatility. This behavior is consistent with a partial adjustment price model where bad news are incorporated faster into current market prices than good news. One possible explanation for this is that the cost of failing to adjust prices downwards is higher. This result is also compatible with Black's (1976) leverage hypothesis. For Vilnius, we find that positive shocks generate more volatility. A possible explanation for this behavior is the liquidity hypothesis of Rockinger and Urga 
(1999). They suggest that in illiquid markets all news generate more liquidity and investors take advantage to dump their positions once greater liquidity has been achieved. Another explanation for the stronger impact of positive shocks is the possibility that, given the short time series, markets have been anticipating mostly positive shocks.

Second, in agreement with other studies (e.g., Koutmos, 1998, Wecker, 1981), the conditional mean response to own past innovations is also asymmetric, with the exception of Riga.

Earlier studies have found that the US is the major source of internationally transmitted information (e.g., Liu and Pan, 1997; Eun and Shim, 1989; Koch and Koch, 1991). In the case of Baltic state stock markets we find that news arriving from New York have stronger impacts on returns in Tallinn and Vilnius, whereas Moscow has a stronger impact on the returns of Riga. We find no evidence of asymmetric impact of good and bad news from New York on returns in Baltic states. The returns spillovers from the US to the stock markets in transition is consistent with the result of Tse et al. (2003), who find significant spillover in the conditional mean return from the US market to the Polish market. A reason for this, they argue, may be due to nonsynchronous trading problem. However, the impact of news from Moscow on returns is asymmetric in Tallinn and Vilnius. In addition, the results indicate that bad news from abroad have stronger impact on returns.

According to our results the impact of low versus high risk in Moscow on volatility in Baltic states is asymmetric. The same pattern can be seen in the responses of the risk from New York for Riga. We find, among other things that there is no volatility spillovers from New York to the stock market in Vilnius. Similar results are found by Tse et al. (2003) for the case of the New York and Warsaw Stock Exchanges. It can be seen that high risk shocks from New York have a stronger effect on volatility in Tallinn, whereas high risk shocks from Moscow have stronger effect on volatility in Vilnius. The overall findings suggest that there are substantial differences among Baltic stock markets, with respect to market adjustment to information arriving from abroad. This supports the findings of Pajuste et al. (2000) that despite common characteristics, Central and Eastern European emerging markets display differences in sensitivity to the risk factors that are affecting the return generating process. This behavior may be caused by, for example, industry composition, ownership and trade structure. 


\section{References}

Bekaert G, Harvey, CR. 1997. Emerging Equity Market Volatility. Journal of Financial Economics 43: 29-77.

Black, F. 1976. Studies of stock price volatility changes. In Proceedings of the Business E Economic Statistics Section. American Statistical Association; 177-181.

Bollerslev, T. 1986. Generalized autoregressive conditional heteroscedasticity. Journal of Econometrics 31: 307-327.

Brännäs K, De Gooijer JG. 1994. Autoregressive-asymmetric moving average models for business cycle data. Journal of Forecasting 13: 529-544.

Brännäs K, De Gooijer, JG. 2004. Asymmetries in Conditional Mean and Variance: Modelling Stock Returns by asMA-asQGARCH. Journal of Forecasting 23: 155-171.

Brännäs K, Nordman, N. 2003a. Conditional Skewness Modelling for Stock Returns. Applied Economics Letters 10: 725-728.

Brännäs K, Nordman, N. 2003b. An Alternative Conditional Asymmetry Specification for Stock Returns. Applied Financial Economics 13: 537-541.

Brännäs K, Ohlsson H. 1999. Asymmetric time series and temporal aggregation. Review of Economics and Statistics 81: 341-344.

Eun C, Shim S. 1989. International transmission of stock market movements. Journal of Financial and Quantitative Analysis 24: 241-256.

Hermes N, Lensink R. 2000. Financial system development in transition economies. Journal of Banking $\&$ Finance 24: 507-524.

Kairys JP, Kruza R, Kumpins R. 2000. Winners and losers from the introduction of continuous variable price trading: Evidence from the Riga Stock Exchange. Journal of Banking \& Finance 24: 603-624.

Koch PD, Koch TW. 1991. Evolution in dynamic linkages across daily national stock indexes. Journal of International Money and Finance 10: 231-251.

Koutmos G, Booth GG. 1995. Asymmetric volatility transmission in international stock markets. Journal of International Money and Finance 14: 747-762.

Koutmos G. 1998. Asymmetries in the Conditional Mean and the Conditional Variance: Evidence From Nine Stock Markets. Journal of Economics and Business 50: 277-290.

Koutmos G. 1999. Asymmetric index stock returns: evidence from the G-7. Applied Economics Letters 6: 817-820.

Liu A, Pan M-S. 1997. Mean and Volatility Spillover Effects in the US and Pacific-Basin Stock Markets. Multinational Finance Journal 1: 47-62.

Pajuste A, Kepitis G, Högfeldt P. 2000. Risk factors and Predictability of Stock Returns in Central and Eastern Europe. Emerging Markets Quarterly Summer: 7-24.

Qian, L. 1998. On maximum likelihood estimators for a threshold autoregression. Journal of Statistical Planning and Inference 75: 21-46.

Rockinger, Urga, G. 2000. A Time Varying Parameter Model to Test for Predictability 
and Integration in Stock Markets of Transition Economies. CEPR Discussion Papers 2346.

Ross SA. 1989. Information and Volatility: The No-Arbitrage Martingale Approach to Timing and Resolution Irrelevancy. The Journal of Finance 44: 1-17.

Sentana E. 1995. Quadratic ARCH models. Review of Economic Studies 62: 639-661.

Tse Y, Wu C, Young A. 2003. Asymmetric information transmission between a transition economy and the U.S. market: evidence from the Warsaw Stock Exchange. Global Finance Journal 14: 319-332.

Wecker WE. 1981. Asymmetric time series. Journal of the American Statistical Association 76: 16-21.

Zakoïan J-M. 1994. Threshold heteroskedastic models. Journal of Economic Dynamics and Control 18: 931-955. 


\section{Appendix}

Table A1: Parameter estimates for the conditional return (ARasMA) models (robust standard errors in parentheses).

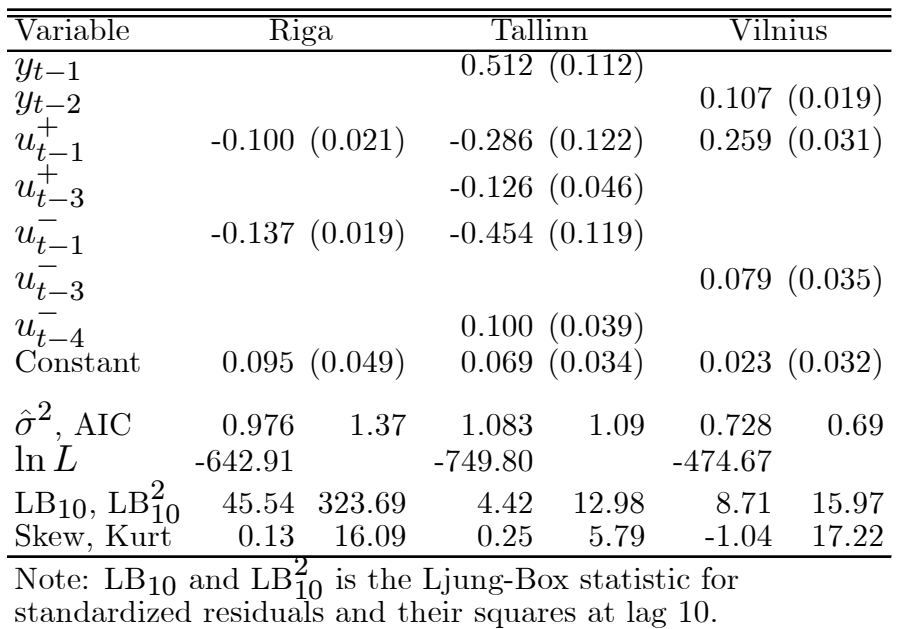


Table A2: Parameter estimates for the conditional return and risk functions of ARasMAasQGARCH models (robust standard errors in parentheses).

\begin{tabular}{|c|c|c|c|c|c|c|}
\hline \multirow[b]{2}{*}{ Variable } & \multicolumn{2}{|c|}{ Riga } & \multicolumn{2}{|c|}{ Tallinn } & \multicolumn{2}{|c|}{ Vilnius } \\
\hline & Return & Risk & Return & Risk & Return & Risk \\
\hline$\overline{y_{t-1}}$ & & & $0.306(0.124)$ & & & \\
\hline$y_{t-2}$ & & & & & $0.140(0.023)$ & \\
\hline$u_{t-1}^{+}$ & $0.123(0.054)$ & & $-0.062(0.133)$ & $-0.016(0.123)$ & $0.321(0.039)$ & $-0.744(0.148)$ \\
\hline$u_{t-2}^{+}$ & & & & $0.226(0.116)$ & & $0.771(0.138)$ \\
\hline$u_{t-3}^{+}$ & & & $-0.066(0.044)$ & & & \\
\hline$u_{t-1}^{-}$ & $-0.041(0.066)$ & $0.289(0.101)$ & $-0.194(0.134)$ & $-0.322(0.122)$ & & $0.787(0.152)$ \\
\hline$u_{t-2}^{-}$ & & $-0.190(0.088)$ & & $0.098(0.122)$ & & $-0.827(0.142)$ \\
\hline$u_{t-3}^{-}$ & & & & & $0.042(0.044)$ & \\
\hline$u_{t-4}^{-}$ & & & $0.103(0.043)$ & & & \\
\hline$u_{t-1}^{2}$ & & $0.641(0.061)$ & & $0.097(0.070)$ & & $0.616(0.114)$ \\
\hline$u_{t-2}^{2}$ & & $-0.320(0.066)$ & & $-0.125(0.064)$ & & $-0.580(0.104)$ \\
\hline$h_{t-1}$ & & $0.678(0.041)$ & & $0.901(0.015)$ & & $0.931(0.012)$ \\
\hline Constant & $0.147(0.032)$ & $0.117(0.019)$ & $0.084(0.036)$ & $-0.019(0.007)$ & $-0.041(0.024)$ & $0.009(0.008)$ \\
\hline$\hat{\sigma}^{2}, \mathrm{AIC}$ & 1.008 & 0.902 & 1.086 & 0.999 & 0.729 & 0.601 \\
\hline $\ln L$ & -414.37 & & -677.09 & & -404.18 & \\
\hline $\mathrm{LB}_{10}, \mathrm{LB}_{10}^{2}$ & 14.72 & 7.30 & 7.28 & 0.87 & 11.63 & 2.90 \\
\hline Skew, Kurt & 0.57 & 4.73 & 0.67 & 7.23 & -1.16 & 18.66 \\
\hline
\end{tabular}

Note: $\mathrm{LB}_{10}$ and $\mathrm{LB}_{10}^{2}$ is the Ljung-Box statistic for standardized residuals and their squares at lag 10. 
Table A3: Parameter estimates for the conditional return and risk functions of ARasMAasQGARCH models with Moscow in conditional return function (robust standard errors in parentheses).

\begin{tabular}{|c|c|c|c|c|c|c|}
\hline \multirow[b]{2}{*}{ Variable } & \multicolumn{2}{|c|}{ Riga } & \multicolumn{2}{|c|}{ Tallinn } & \multicolumn{2}{|c|}{ Vilnius } \\
\hline & Return & Risk & Return & Risk & Return & Risk \\
\hline$\overline{y_{t-1}}$ & & & $0.212(0.110)$ & & & \\
\hline$y_{t-2}$ & & & & & $0.111(0.024)$ & \\
\hline$u_{t-1}^{+}$ & $-0.124(0.055)$ & & $0.008(0.122)$ & $0.172(0.122)$ & $0.319(0.049)$ & $-0.698(0.130)$ \\
\hline$u_{t-2}^{+}$ & & & & $0.058(0.128)$ & & $0.843(0.101)$ \\
\hline$u_{t-3}^{+}$ & & & $-0.093(0.035)$ & & & \\
\hline$u_{t-1}^{-}$ & $-0.045(0.068)$ & $0.276(0.108)$ & $-0.077(0.119)$ & $-0.542(0.119)$ & & $0.628(0.142)$ \\
\hline$u_{t-2}^{-}$ & & $-0.185(0.093)$ & & $0.323(0.124)$ & & $-0.575(0.108)$ \\
\hline$u_{t-3}^{-}$ & & & & & $0.075(0.041)$ & \\
\hline$u_{t-4}^{-}$ & & & $0.103(0.042)$ & & & \\
\hline$u_{t-1}^{2}$ & & $0.637(0.065)$ & & $0.038(0.056)$ & & $0.557(0.103)$ \\
\hline$u_{t-2}^{2}$ & & $-0.320(0.069)$ & & $-0.074(0.053)$ & & $-0.259(0.084)$ \\
\hline$h_{t-1}$ & & $0.679(0.042)$ & & $0.905(0.018)$ & & $0.456(0.052)$ \\
\hline$x_{t}^{+}$ & $-0.024 \quad(0.026)$ & & $0.063(0.021)$ & & $0.002(0.015)$ & \\
\hline$x_{t-1}^{+}$ & $-0.019 \quad(0.028)$ & & $0.031(0.022)$ & & $0.019(0.015)$ & \\
\hline$x_{t-2}^{+}$ & & & $-0.033(0.022)$ & & $-0.026(0.014)$ & \\
\hline$x_{t-3}^{+}$ & & & $0.025(0.023)$ & & & \\
\hline$x_{t}^{-}$ & $0.059 \quad(0.025)$ & & $0.086(0.017)$ & & $0.095(0.013)$ & \\
\hline$x_{t-1}^{-}$ & $-0.010 \quad(0.029)$ & & $-0.013(0.024)$ & & $0.042(0.010)$ & \\
\hline$x_{t-2}^{-}$ & & & $0.077(0.021)$ & & $0.026(0.016)$ & \\
\hline $\begin{array}{l}x_{t-3}^{-} \\
\text {Constant }\end{array}$ & $0.205 \quad(0.051)$ & $0.115(0.019)$ & $\begin{array}{l}0.025(0.021) \\
0.171(0.045)\end{array}$ & $-0.025(0.007)$ & $0.136(0.038)$ & $0.181(0.041)$ \\
\hline $\begin{array}{l}\hat{\sigma}^{2}, \mathrm{AIC} \\
\ln L\end{array}$ & $\begin{array}{r}0.98 \\
-410.69\end{array}$ & 0.90 & $\begin{array}{r}1.04 \\
-647.99\end{array}$ & 0.97 & $\begin{array}{r}0.72 \\
-361.53\end{array}$ & 0.54 \\
\hline $\mathrm{LB}_{10}, \mathrm{LB}_{10}^{2}$ & 11.03 & 9.64 & 6.13 & 1.00 & 6.26 & 2.34 \\
\hline Skew, Kurt & 0.55 & 4.74 & 0.69 & 6.92 & -0.57 & 7.98 \\
\hline
\end{tabular}

Note: $\mathrm{LB}_{10}$ and $\mathrm{LB}_{10}^{2}$ is the Ljung-Box statistic for standardized residuals and their squares at lag 10. 
Table A4: Parameter estimates for the conditional return and risk functions of ARasMAasQGARCH models with New York in conditional return function (robust standard errors in parentheses).

\begin{tabular}{|c|c|c|c|c|c|c|}
\hline \multirow[b]{2}{*}{ Variable } & \multicolumn{2}{|c|}{ Riga } & \multicolumn{2}{|c|}{ Tallinn } & \multicolumn{2}{|c|}{ Vilnius } \\
\hline & Return & Risk & Return & Risk & Return & Risk \\
\hline$y_{t-1}$ & & & $0.144(0.078)$ & & & \\
\hline$y_{t-2}$ & & & & & $0.105(0.023)$ & \\
\hline$u_{t-1}^{+}$ & $-0.119(0.058)$ & & $0.125(0.087)$ & $0.087(0.130)$ & $0.261(0.040)$ & $-0.816(0.143)$ \\
\hline$u_{t-2}^{+}$ & & & & $0.165(0.124)$ & & $0.844(0.129)$ \\
\hline$u_{t-3}^{+}$ & & & $-0.055(0.038)$ & & & \\
\hline$u_{t-1}^{-}$ & $-0.044(0.067)$ & $0.300(0.104)$ & $-0.077(0.088)$ & $-0.482(0.123)$ & & $0.898(0.141)$ \\
\hline$u_{t-2}^{-}$ & & $-0.200(0.090)$ & & $0.245(0.124)$ & & $-0.922(0.126)$ \\
\hline$u_{t-3}^{-}$ & & & & & $0.033(0.043)$ & \\
\hline$u_{t-4}^{-}$ & & & $0.088(0.039)$ & & & \\
\hline$u_{t-1}^{2}$ & & $0.649(0.062)$ & & $0.064(0.065)$ & & $0.691(0.110)$ \\
\hline$u_{t-2}^{2}$ & & $-0.327(0.066)$ & & $-0.100(0.060)$ & & $-0.638(0.098)$ \\
\hline$h_{t-1}$ & & $0.680(0.040)$ & & $0.902(0.015)$ & & $0.912(0.019)$ \\
\hline$x_{t-1}^{+}$ & $-0.015(0.046)$ & & $0.218(0.040)$ & & $0.037(0.029)$ & \\
\hline$x_{t-1}^{-}$ & $-0.006 \quad(0.043)$ & & $0.247(0.036)$ & & $0.144(0.030)$ & \\
\hline Constant & $0.149 \quad(0.039)$ & $0.116(0.019)$ & $0.076(0.039)$ & $-0.034(0.008)$ & $0.033(0.027)$ & $0.018(0.011)$ \\
\hline $\begin{array}{l}\hat{\sigma}^{2}, \mathrm{AIC} \\
\ln L\end{array}$ & $\begin{array}{r}0.981 \\
-414.24\end{array}$ & 0.91 & $\begin{array}{r}1.022 \\
-633.34\end{array}$ & 0.94 & $\begin{array}{r}0.718 \\
-385.27\end{array}$ & 0.58 \\
\hline $\mathrm{LB}_{10}, \mathrm{LB}_{10}^{2}$ & 11.74 & 8.97 & 8.67 & 0.74 & 11.92 & 1.91 \\
\hline Skew, Kurt & 0.52 & 4.91 & 0.67 & 7.85 & -1.12 & 17.66 \\
\hline
\end{tabular}

Note: $\mathrm{LB}_{10}$ and $\mathrm{LB}_{10}^{2}$ is the Ljung-Box statistic for standardized residuals and their squares at lag 10. 
Table A5: Parameter estimates for the conditional return and risk functions of ARasMAasQGARCH models with Moscow in the functions (robust standard errors in parentheses).

\begin{tabular}{|c|c|c|c|c|c|c|}
\hline \multirow[b]{2}{*}{ Variable } & \multicolumn{2}{|c|}{$\overline{\text { Riga }}$} & \multicolumn{2}{|c|}{ Tallinn } & \multicolumn{2}{|c|}{$\overline{\overline{V i l n i u s}}$} \\
\hline & Return & Risk & Return & Risk & Return & Risk \\
\hline$\overline{y_{t-1}}$ & & & $0.405(0.117)$ & & & \\
\hline$y_{t-2}$ & & & & & $0.107(0.026)$ & \\
\hline$u_{t-1}^{+}$ & $-0.153(0.059)$ & & $-0.150(0.131)$ & $0.074(0.128)$ & $0.315(0.050)$ & $-0.401(0.119)$ \\
\hline$u_{t-2}^{+}$ & & & & $0.105(0.127)$ & & $0.587(0.100)$ \\
\hline$u_{t-3}^{+}$ & & & $-0.098(0.041)$ & & & \\
\hline$u_{t-1}^{-}$ & $-0.027(0.074)$ & $0.186(0.105)$ & $-0.344(0.130)$ & $-0.400(0.133)$ & & $0.356(0.125)$ \\
\hline$u_{t-2}^{-}$ & & $-0.037(0.094)$ & & $0.199(0.131)$ & & $-0.478(0.102)$ \\
\hline$u_{t-3}^{-}$ & & & & & $0.059(0.046)$ & \\
\hline$u_{t-4}^{-}$ & & & $0.101(0.040)$ & & & \\
\hline$u_{t-1}^{2}$ & & $0.521(0.064)$ & & $0.075(0.069)$ & & $0.370(0.087)$ \\
\hline$u_{t-2}^{2}$ & & $-0.185(0.070)$ & & $-0.108(0.063)$ & & $-0.251(0.073)$ \\
\hline$h_{t-1}$ & & $0.608(0.050)$ & & $0.925(0.016)$ & & $0.658(0.045)$ \\
\hline$x, z_{t}^{+}$ & $-0.035(0.030)$ & & $0.055(0.022)$ & $0.034(0.018)$ & $-0.005(0.017)$ & \\
\hline$x, z_{t-1}^{+}$ & $-0.026(0.031)$ & $-0.006(0.004)$ & $0.014(0.023)$ & $-0.080(0.032)$ & $0.024(0.016)$ & $-0.033(0.009)$ \\
\hline$x, z_{t-2}^{+}$ & & & $-0.033(0.021)$ & $0.045(0.016)$ & $-0.009(0.017)$ & $0.109(0.017)$ \\
\hline$x, z_{t-3}^{+}$ & & & $0.027(0.022)$ & & & $-0.113(0.015)$ \\
\hline$x, z_{t-4}^{+}$ & & & & & & $0.041(0.010)$ \\
\hline$x, z_{t}^{-}$ & $0.056(0.029)$ & & $0.089(0.018)$ & $0.047(0.052)$ & $0.055(0.015)$ & \\
\hline$x, z_{t-1}^{-}$ & $-0.010(0.032)$ & $0.040(0.009)$ & $-0.025(0.023)$ & $-0.046(0.099)$ & $0.029(0.014)$ & $0.069(0.032)$ \\
\hline$x, z_{t-2}^{-}$ & & & $0.054(0.019)$ & $-0.005(0.051)$ & $0.018(0.018)$ & $-0.137(0.063)$ \\
\hline$x, z_{t-3}^{-}$ & & & $0.017(0.023)$ & & & $0.094(0.063)$ \\
\hline $\begin{array}{l}x, z_{t-4}^{-} \\
\text {Constant }\end{array}$ & $0.228(0.054)$ & $0.287(0.048)$ & $0.104(0.042)$ & $-0.031(0.009)$ & $0.076(0.043)$ & $\begin{array}{r}-0.019(0.036) \\
0.080(0.028)\end{array}$ \\
\hline $\begin{array}{l}\hat{\sigma}^{2}, \mathrm{AIC} \\
\ln L\end{array}$ & $\begin{array}{r}0.976 \\
-403.52\end{array}$ & 0.89 & $\begin{array}{r}1.038 \\
-637.25\end{array}$ & 0.96 & $\begin{array}{r}0.719 \\
-338.15\end{array}$ & 0.53 \\
\hline $\mathrm{LB}_{10}, \mathrm{Ll}$ & 20 & & 4.69 & & 8.85 & 2.04 \\
\hline Skew, Kurt & 0.63 & 4.36 & 0.58 & 5.89 & -0.40 & 6.20 \\
\hline
\end{tabular}

Note: $\mathrm{LB}_{10}$ and $\mathrm{LB}_{10}^{2}$ is the Ljung-Box statistic for standardized residuals and their squares at lag 10. 
Table A6: Parameter estimates for the conditional return and risk functions of ARasMAasQGARCH models with New York in the functions (robust standard errors in parentheses).

\begin{tabular}{|c|c|c|c|c|c|c|}
\hline \multirow[b]{2}{*}{ Variable } & \multicolumn{2}{|c|}{$\overline{\text { Riga }}$} & \multicolumn{2}{|c|}{ Tallinn } & \multicolumn{2}{|c|}{$\begin{array}{c}\text { Vilnius } \\
\end{array}$} \\
\hline & Return & Risk & Return & Risk & Return & Risk \\
\hline$y_{t-1}$ & & & $0.106(0.044)$ & & & \\
\hline$y_{t-2}$ & & & & & $0.109(0.024)$ & \\
\hline$u_{t-1}^{+}$ & $-0.145(0.059)$ & & $0.164(0.083)$ & $0.113(0.129)$ & $0.256(0.041)$ & $-0.687(0.135)$ \\
\hline$u_{t-2}^{+}$ & & & & $0.089(0.124)$ & & $0.705(0.117)$ \\
\hline$u_{t-3}^{+}$ & & & $-0.049(0.037)$ & & & \\
\hline$u_{t-1}^{-}$ & $-0.040(0.069)$ & $0.219(0.110)$ & $-0.044(0.089)$ & $-0.434(0.127)$ & & $0.819(0.135)$ \\
\hline$u_{t-2}^{-}$ & & $-0.162(0.091)$ & & $0.228(0.127)$ & & $-0.848(0.117)$ \\
\hline$u_{t-3}^{-}$ & & & & & $0.013(0.049)$ & \\
\hline$u_{t-4}^{-}$ & & & $0.098(0.041)$ & & & \\
\hline$u_{t-1}^{2}$ & & $0.640(0.063)$ & & $0.076(0.069)$ & & $0.574(0.100)$ \\
\hline$u_{t-2}^{2}$ & & $-0.338(0.066)$ & & $-0.109(0.064)$ & & $-0.502(0.087)$ \\
\hline$h_{t-1}$ & & $0.694(0.039)$ & & $0.918(0.016)$ & & $0.855(0.028)$ \\
\hline$x, z_{t-1}^{+}$ & $-0.015 \quad(0.046)$ & $0.020(0.009)$ & $0.206(0.044)$ & $0.269(0.112)$ & $0.035(0.026)$ & $0.083(0.051)$ \\
\hline$x, z_{t-2}^{+}$ & & & & $-0.117(0.238)$ & & $-0.228(0.094)$ \\
\hline$x, z_{t-3}^{+}$ & & & & $-0.427(0.218)$ & & $0.235(0.078)$ \\
\hline$x, z_{t-4}^{+}$ & & & & $0.287(0.094)$ & & $-0.097(0.044)$ \\
\hline$x, z_{t-1}^{-}$ & $-0.001 \quad(0.042)$ & $-0.068(0.020)$ & $0.272(0.035)$ & $-0.019(0.339)$ & $0.130(0.030)$ & $0.354(0.152)$ \\
\hline$x, z_{t-2}^{-}$ & & & & $-0.221(0.678)$ & & $-0.221(0.314)$ \\
\hline$x, z_{t-3}^{-}$ & & & & $0.220(0.498)$ & & $-0.771(0.319)$ \\
\hline $\begin{array}{l}x, z_{t-4}^{-} \\
\text {Constant }\end{array}$ & $0.158(0.040)$ & $0.067(0.020)$ & $0.092(0.044)$ & $\begin{array}{l}-0.018(0.205) \\
-0.046(0.008)\end{array}$ & $0.019(0.029)$ & $\begin{array}{l}0.649(0.158) \\
0.053(0.018)\end{array}$ \\
\hline $\begin{array}{l}\hat{\sigma}^{2}, \mathrm{AIC} \\
\ln L\end{array}$ & $\begin{array}{r}0.979 \\
-411.06\end{array}$ & 0.90 & $\begin{array}{r}1.022 \\
-617.69\end{array}$ & 0.93 & $\begin{array}{r}0.719 \\
-369.71\end{array}$ & 0.57 \\
\hline $\mathrm{LB}_{10}, \mathrm{LB}_{10}^{2}$ & 11.46 & 9.23 & 9.20 & 1.11 & 11.58 & 1.43 \\
\hline Skew, Kurt & 0.53 & 4.69 & 0.48 & 6.21 & -0.92 & 14.31 \\
\hline
\end{tabular}

Note: $\mathrm{LB}_{10}$ and $\mathrm{LB}_{10}^{2}$ is the Ljung-Box statistic for standardized residuals and their squares at lag 10. 